\section{Body weight classification}

Tagree with Simone Lemieux and as1 sociates $^{1}$ that further discussion is warranted regarding the strengths and limitations of the 2003 Canadian Guidelines for Body Weight Classification in Adults. ${ }^{2}$ However, several points in the commentary might mislead health care providers about the interpretation of these guidelines and their use in clinical practice.

First, Lemieux and associates state that the waist circumference cut-off values used in the guidelines "have not yet been validated." However, these cutoffs for assessing health risk have been validated in several studies, including 2 population-based studies involving 23000 adults in Canada and the United States. ${ }^{3,4}$

Second, Lemieux and associates claim that "people who are in the overweight range while showing low levels of abdominal adipose tissue generally display a risk profile similar to that of nonobese subjects," thereby suggesting that body mass index (BMI) is not a useful predictor of health risk in the one-third of Canadian adults who are overweight. ${ }^{5}$ Although it is plausible that a multitiered classification of waist circumference might identify overweight people with a low waist circumference as having the same health risk as non-overweight people, ${ }^{6}$ there is a lack of consensus on how to stratify waist circumference according to health risk.

Third, Lemieux and associates are concerned that the lowering of the BMI cut-off for "underweight" in the guidelines from $20.0 \mathrm{~kg} / \mathrm{m}^{2}$ to $18.5 \mathrm{~kg} / \mathrm{m}^{2}$ might lead to false identification of elderly people or young women in the $18.5-20 \mathrm{~kg} / \mathrm{m}^{2}$ range as having a normal weight when they may be malnourished or, with young women, have an eating disorder. The potential health risks in adults older than 65 years with a BMI in the 18.5-to-low 20s range was acknowledged in the guidelines, ${ }^{2}$ and the need for further health assessment was suggested for such individuals. I concur as to the potential of underrecognizing eating disorders in young women with a BMI in the 18.5-20 $\mathrm{kg} / \mathrm{m}^{2}$ range. However, according to prespecified criteria, ${ }^{7}$ the diagnosis of anorexia nervosa is considered in people with a BMI less than $17.5 \mathrm{~kg} / \mathrm{m}^{2}$, which is within the underweight range in the guidelines.

Fourth, Lemieux and associates suggest that, on the basis of the weight classification guidelines, people with a BMI of $25.0-29.9 \mathrm{~kg} / \mathrm{m}^{2}$ will be labelled as overweight and may be under greater pressure to lose weight. This is not the aim of the guidelines, which clearly state that "the [BMI] cut-off points are not intended as targets for intervention purposes in individuals." The possibility that misinformed individuals will use the guidelines to initiate weight loss cannot be excluded, particularly since $6 \%$ of men and $24 \%$ of women with normal weight are attempting weight loss. ${ }^{8}$ The intent of the guidelines is to increase awareness of body weight classification and to act as a catalyst for people to review their health status with their health care providers.

Finally, Lemieux and associates question the clinical applicability of the weight classification, indicating that " $[\mathrm{m}]$ any factors beyond BMI influence health risk" and that "a number of important clinical factors are absent from the report: special considerations for elderly people, ethnic differences, physical activity and diet." However, the guidelines state that "at the individual level, the [BMI and waist circumference] system should be used as one part of a more comprehensive assessment of health risk," and there are separate sections on how to interpret $\mathrm{BMI}$ and waist circumference in adults older than 65 years, ethnic and racial groups, and physically fit individuals. Table 1 outlines how BMI and waist circumference, which are easy-to-perform bedside measurements, can be used as part of a health assessment in adults.

\section{James D. Douketis}

Member, Expert Working Group for the Canadian Guidelines for Body Weight

Classification in Adults

Department of Medicine

McMaster University

St. Joseph's Healthcare

Hamilton, Ont.

\section{References}

1. Lemieux S, Mongeau L, Paquette MC, Laberge $\mathrm{S}$, Lachance B; for the members of the GTPPP (Quebec Provincial Working Group on Weight Related Issues). Health Canada's new guidelines for body weight classification in adults: challenges and concerns [editorial]. CMAf 2004;171 (11):1361-3.

2. Office of Nutrition Policy and Promotion. Canadian guidelines for body weight classification in adults. Ottawa: Health Canada: 2003. Available: www.hc-sc.gc.ca/hpfb-dgpsa/onppbppn/cg_bwc_introduction_e.html (accessed 2005 Jan 28).

3. Janssen I, Katzmarzyk PT, Ross R. Body mass index, waist circumference, and health risk: evidence in support of current National Institutes of Health guidelines. Arch Intern Med 2002;162: 2074-9.

4. Ardern CI, Katzmarzyk PT, Janssen I, Ross R. Discrimination of health risk by combined body mass index and waist circumference [published erratum in Obes Res 2003;11:491]. Obes Res 2003; 11:135-42.

5. Body mass index (BMI), by sex, household population aged 18 and over excluding pregnant women, Canada, provinces, territories, health regions and peer groups, 2003. Ottawa: Statistics Canada. Available: www.statcan.ca/english/freepub/82 221-XIE/00604/tables/html/1228_03.htm (accessed 2005 Jan 31).

6. Janssen I, Katzmarzyk PT, Ross R. Waist circumference and not body mass index explains obesity-related health risk. Am 7 Clin Nutr 2004;79:379-84.

7. Diagnostic and statistical manual of mental disorders. 4th ed. Washington: American Psychiatric Association; 2000. p. 583-4.

8. Kruger J, Galuska DA, Serdulla MK, Jones DA
Table 1: Health risk classification using both body mass index and waist circumference

\begin{tabular}{lccc}
\hline & \multicolumn{3}{c}{ Body mass index, $\mathrm{kg} / \mathrm{m}^{2}$} \\
\cline { 2 - 4 } Waist circumference, cm & $\begin{array}{c}18.5-24.9 \\
\text { (normal) }\end{array}$ & $\begin{array}{c}25.0-29.9 \\
\text { (overweight) }\end{array}$ & $\begin{array}{c}30.0-34.9 \\
\text { (obese class I) }\end{array}$ \\
\hline $\begin{array}{l}\text { Men: }<102 \\
\text { Women: }<88\end{array}$ & Least risk & Increased risk & High risk \\
$\begin{array}{l}\text { Men: } \geq 102 \\
\text { Women: } \geq 88\end{array}$ & Increased risk & High risk & Very high risk \\
\hline
\end{tabular}


Attempting to lose weight: specific practices among U.S. adults. Am 7 Prev Med 2004;264: $402-6$.

DOI:10.1503/cmaj.1050005

\section{[Three of the authors respond:]}

$\mathrm{J}^{2}$ ames Douketis notes that waist circumference cut-offs have been validated, citing an excellent paper by Janssen and collaborators. ${ }^{1}$ Those authors demonstrated that the use of waist circumference cut-off points helps to identify subjects at increased health risk within normal-weight, overweight and class I obese BMI categories, but their study was not a validation of waist cutoffs. Accordingly, they acknowledged that their results do not imply that the specific cut-off values of $102 \mathrm{~cm}$ for men and $88 \mathrm{~cm}$ for women are the ideal threshold values denoting increased risk. ${ }^{1}$ They also pointed out that the waist circumference values that best predict health risk within different BMI categories are still unknown. ${ }^{1}$

We acknowledge that more research is needed on waist circumference cutoffs and on other indicators to better assess the health risks of people in the overweight category, especially given that decreasing the BMI cut-off for this category (from 27 to $25 \mathrm{~kg} / \mathrm{m}^{2}$ ) has resulted in increased heterogeneity in terms of health risk. ${ }^{2}$

In addition, we wish to stress our concern about reducing the lower limit for the normal weight category (from 20 to $18.5 \mathrm{~kg} / \mathrm{m}^{2}$ ). In our current sociocultural context, where thinness is highly valued, such changes to BMI categories could intensify people's (notably women's) excessive concern about body weight, ${ }^{3}$ which unfortunately may lead them to seek rapid weight loss and to use unhealthy and even dangerous weight loss methods. ${ }^{4}$ The impact of these changes in BMI classification is not trivial and must be recognized. Reducing the lower BMI cut-off for normal weight (to $18.5 \mathrm{~kg} / \mathrm{m}^{2}$ ) may lead to risks associated with delayed identification of eating disorders, but such a change can also prevent early recognition of disordered attitudes and behaviours concerning eating and physical activity, a situation that precedes the onset of eating disorders and affects more adult women than do eating disorders. ${ }^{5}$

Although Douketis is correct in stating that the guidelines are not designed for intervention purposes in individuals, the BMI remains well known to the public. BMI calculators can be found easily on the Internet and in magazines, and it is impossible to control how people will interpret their $\mathrm{BMI}$ in the absence of advice from a health care provider.

Finally, we agree that more discussion is needed concerning the guidelines. It is essential for health care providers to be better informed on how to interpret and use the new weight classification system.

\section{Simone Lemieux}

Département des sciences des aliments et de nutrition

Université Laval

Sainte-Foy, Que.

Marie-Claude Paquette

Lyne Mongeau
Institut national de santé publique du Québec

Sainte-Foy, Que.

For the members of the GTPPP (Québec Provincial Working Group on Weight Related Issues)

\section{References}

1. Janssen I, Katzmarzyk PT, Ross R. Body mass index, waist circumference, and health risk: evidence in support of current National Institutes of Health guidelines. Arch Intern Med 2002; 162:2074-9.

2. Lemieux S, Mongeau L, Paquette MC, Laberge S, Lachance B; for the members of the GTPPP (Quebec Provincial Working Group on Weight Related Issues). Health Canada's new guidelines for body weight classification in adults: challenges and concerns [editorial]. CMAJ 2004; 171(11):1361-3.

3. Green KL, Cameron R, Polivy J, Cooper K, Liu L, Leiter L, et al. Weight dissatisfaction and weight loss attempts among Canadian adults. Canadian Heart Health Surveys Research Group. CMA7 1997;157(Suppl 1):S17-25.

4. Berg FM. Health risks associated with weight loss and obesity treatment programs. 7 Soc Issues 1999;55:277-97.

5. Neumark-Sztainer D. The weight dilemma: a range of philosophical perspectives. Int 7 Obes 1999;23:S31-7.

DOI:10.1503/cmaj.1050061

\section{Correction}

Tn a recent Public Health article, ${ }^{1}$ the 1 term Plasmodium falciparum mistakenly read Plasmodium falciform.

\section{Reference}

1. Weir E. Malaria update. CMA7 2005;172(4):473. DOI:10.1503/cmaj.050434 